\title{
Seamless Transfer Scheme With Unified Control Core for Paralleled Systems
}

Liu, Hongpeng; Zhang, Wei; Sun, Bainan; Loh, Poh Chiang; Wang, Wei; Xu, Dianguo ; Blaabjerg, Frede

Published in:

I E E E Transactions on Power Electronics

Link to article, DOI:

10.1109/TPEL.2018.2872326

Publication date:

2019

Document Version

Peer reviewed version

Link back to DTU Orbit

Citation $(A P A)$ :

Liu, H., Zhang, W., Sun, B., Loh, P. C., Wang, W., Xu, D., \& Blaabjerg, F. (2019). Seamless Transfer Scheme With Unified Control Core for Paralleled Systems. I E E E Transactions on Power Electronics, 34(7), 6286-6298. https://doi.org/10.1109/TPEL.2018.2872326

\section{General rights}

Copyright and moral rights for the publications made accessible in the public portal are retained by the authors and/or other copyright owners and it is a condition of accessing publications that users recognise and abide by the legal requirements associated with these rights.

- Users may download and print one copy of any publication from the public portal for the purpose of private study or research.

- You may not further distribute the material or use it for any profit-making activity or commercial gain

- You may freely distribute the URL identifying the publication in the public portal 


\title{
Seamless Transfer Scheme With Unified Control Core for Paralleled Systems
}

\author{
Hongpeng Liu, Member, IEEE, Wei Zhang, Bainan Sun, Student Member, IEEE, Poh Chiang Loh, \\ Wei Wang, Member, IEEE, Dianguo Xu, Fellow, IEEE, and Frede Blaabjerg, Fellow, IEEE
}

\begin{abstract}
In distributed generation, grid-connected and islanded modes are essential, but usually they have different control cores to satisfy their respective control targets. Transferring between the cores may therefore lead to prominent disturbances, if the cores are complex and noticeably different in structures. To introduce seamlessness, some techniques have been recommended, but they usually lack unification of control blocks for the front dc-dc converter and rear dc-ac inverter. Moreover, when connected to the grid, some seamless techniques do not control the grid current directly. Hence, its dynamics may be slow, in addition to distortion caused by grid-voltage harmonics. When islanded, most techniques also use two control loops to regulate a drooped voltage across local loads. This double-loop structure works fine, but it has more state variables to change during a transfer of modes, which may not be as seamless. An alternative technique has thus been proposed here, whose purpose is to identify a simple unified control core, which will remain unchanged during the mode transfer. The transfer may then be viewed as a normal change of power reference, instead of an internal change of control structure. Hence, seamless operation may be ensured, as it is tested in simulations and experiments. These tests have additionally shown that the proposed scheme can regulate the grid current directly when connected to the grid, without compromising the droop-voltage regulation when islanded.
\end{abstract}

Index Terms-Distributed generation, Seamless transfer, Droop control, Parallel inverters, Small-signal analysis.

\section{INTRODUCTION}

$\mathrm{D}$ istributed generation (DG) is an ideal approach to integrate various renewable resources such as photovoltaic (PV), wind, hydro and tidal systems [1]. A vital component to enable the integration is the power converter, which must usually operate in either the grid-connected or islanded mode. In the

Manuscript received April 22, 2018; revised June 26, 2018; accepted September 22, 2018. This work was supported by the National Key R\&D Program of China under Grant 2016YFE0102800.

Hongpeng Liu, Wei Zhang, Wei Wang, and Dianguo Xu are with the Department of Electrical Engineering, Harbin Institute of Technology, Harbin 150001, China (e-mail: 1hp602@hit.edu.cn; mrhhzw@126.com; wangwei602@hit.edu.cn; xudiang@hit.edu.cn).

Bainan Sun is with Department of Electrical Engineering, Technical University of Denmark, Kgs. Lyngby 2800, Denmark (baisun@elektro.dtu.dk).

Poh Chiang Loh is with Department of Electronic Engineering, Chinese University of Hong Kong, Hong Kong 999077, China (e-mail: epcloh@gmail.com).

Frede Blaabjerg is with Department of Energy Technology, Aalborg University, Aalborg DK-9220, Denmark (fbl@et.aau.dk). former mode, each renewable source usually operates with maximum power generated to power local loads and inject to the grid [2]. This changes during fault, where the IEEE 1547-2003 standard demands the same source to continue powering the local loads in an island [3]. And it must also provide the necessary voltage regulation due to the absence of grid [4], [5]. Thus, control targets in both modes are noticeably different, which may sometimes burden the transfers between modes with inrush currents and even system crashes [6], [7].

Several studies have therefore been started to find a controller that will not change significantly during each seamless transfer. One possibility involves the indirect control of grid current through regulating voltage of an L-type filter when connected to the grid [8], [9]. The same voltage regulator may then be utilized in both modes. However, indirect control may be complex due to the presence of nonlinear variables. Its voltage-vector relationship, formulated in the steady state, may also not predict its dynamic response sufficiently.

Another seamless method has therefore relied on a weighted combination of voltage and current control [10], where the main concern is to analyze an uncontrollable state, occurring during the usually narrow transfer delay. Nevertheless, a proper weight selection for that method has not been thoroughly clarified. State feedback control from [11] may therefore be deliberated instead, but only if high-speed sampling and unrestricted geographical data transfer are realizable. Otherwise, the unified control method in [12] may be evaluated, where a strict requirement is to synchronize with the grid accurately. To ensure that, [12] depends on detecting voltage and frequency differences, before determining the proper instant for grid connection. This renders it vulnerable to system parameter fluctuations and voltage / frequency detection errors.

Because of that, other seamless transfer methods have instead focused on reducing the transient time, and hence enhancing the robustness of the controlled system. For example, in [13], a sophisticated method has used a current controller and a feedforward voltage controller for suppressing the short overvoltage duration when connected to the grid. Although effective, the method has not considered other abnormal conditions such as frequency distortion. Another method has used variable-structure and adaptive transient droop control for actively damping large-signal disturbances [14], but it requires fast computation and communication buses. A synchronization technique has also been proposed in [15], where both positiveand negative-sequence voltage harmonics have been processed, 
in addition to their fundamental components. However, that method has only been implemented at the secondary level of a hierarchical control structure.

Other alternatives include the quick response seamless transfer control scheme for three-phase inverters proposed in [16], but that structure is not suitable for parallel inverters. Another hierarchical control architecture capable of seamless transition between operating modes has been proposed in [17]. However, it comprises a microgrid central controller (MGCC) and a communication link, which may degrade system reliability. A method, that utilizes an observer-based capacitor current senseless control for seamless transfer, has also been suggested in [18]. Its principle is to use an observed capacitor current for reducing impacts from the sampled capacitor current ripple during the transfer of modes, but errors from its phase-locked loop (PLL) may affect accuracy of the observer. Another scheme based on an unchanged control structure during mode transition has been proposed in [19], but its hysteresis current control demands a high switching frequency and hence an increased system loss.

In [20], a method has been tried, where the grid condition has been analyzed by detecting the grid frequency, before current control and feedforward voltage control have been utilized for reducing transient time. Some drawbacks accompanying it are vulnerabilities to frequency fluctuation and local load variation. Moreover, the design of feedforward control has not been thoroughly detailed. A soft-start virtual impedance method may hence be considered to lessen the transfer impact, but it may require a high and accurate sampling rate for detecting the grid frequency [21]. More importantly, most of these methods have focused on seamless transfer for either only a single renewable system or the master unit in a hierarchical system. For paralleled systems, they may have to incorporate droop control, which by far, has been widely utilized for enhancing load sharing and stability when islanded [22]-[24]. Because of that, some studies have expanded the usage of droop control to the grid-connected mode, in order to achieve seamless transfer [25]-[27]. An effort in [28] has even tried to introduce three mutually interacting droop control loops for better power regulation and stability.

Despite that, most droop schemes have been indifferently implemented as a voltage regulator, which when in the grid-connected mode, may cause current distortion due to grid voltage harmonics, since the grid current has not been regulated directly. An alternative seamless transfer scheme with a unified control core has hence been proposed here, whose features are better contrasted by first reviewing drawbacks of two existing schemes in details in Section II. Section III then describes the proposed scheme operating in islanded and grid-connected modes, and during their seamless transfer. This is followed by small-signal modelling and stability analysis in Section IV, and discussion of simulation and experimental results in Sections V and VI, respectively. The final conclusion is then drawn in Section VII.

\section{EXISTING TRANSFER SCHEMES}

To better disscuss existing transfer schemes, two of them reported in the literature are described below.

\section{A. Technique from [25]}

Fig. 1 shows the control block diagram from [25], which regardless of grid-connected or islanded mode, requires the computation of active power $P$ and reactive power $Q$ from the sampled ac output voltage $v_{o}$ and current $i_{o}$. The computation has further been low-pass filtered with a bandwidth, which will slow down the process significantly. The calculated $P$ and $Q$, together with their references $P^{*}$ and $Q^{*}$, can then be substituted to the following droop equations to find magnitude $E$ and angular frequency $\omega$ of the output voltage reference $v_{\text {ref }}^{*}$, when islanded.

$$
\begin{aligned}
& \omega=\omega^{*}-k_{p}\left(P^{*}-P\right) \\
& E=E^{*}-k_{q}\left(Q^{*}-Q\right)
\end{aligned}
$$

The block diagrams showing these droop equations are found in the dashed box in Fig. 1, which elementarily, are simply two proportional terms with gains $k_{p}$ and $k_{q}$ (also known as droop coefficients). No integral terms should be added, if proper local load sharing is necessary among multiple islanded sources and their converters. On the other hand, they should be included when connected to the grid, during which each source is usually required to inject its maximum power, rather than achieving power sharing. The included integral terms will then ensure the source track to its maximum power reference accurately. The scheme in Fig. 1 will therefore operate well, but its performance may sometimes be compromised by the following drawbacks.

- The generated voltage reference $v_{r e f}^{*}$, consisting only of fundamental component, is tracked by a double-loop controller, even when connected to the grid. The grid current has therefore not been controlled directly, which may result in distortion caused by grid voltage harmonics.

- In cases where a front boost converter has been inserted between the source and rear inverter, the intermediate dc-link voltage has to be regulated by the boost converter, if the scheme in Fig. 1 for the inverter remains unchanged. This may not be preferred, since the power generated by the source is not controlled by the immediate front converter receiving it in both operating modes.

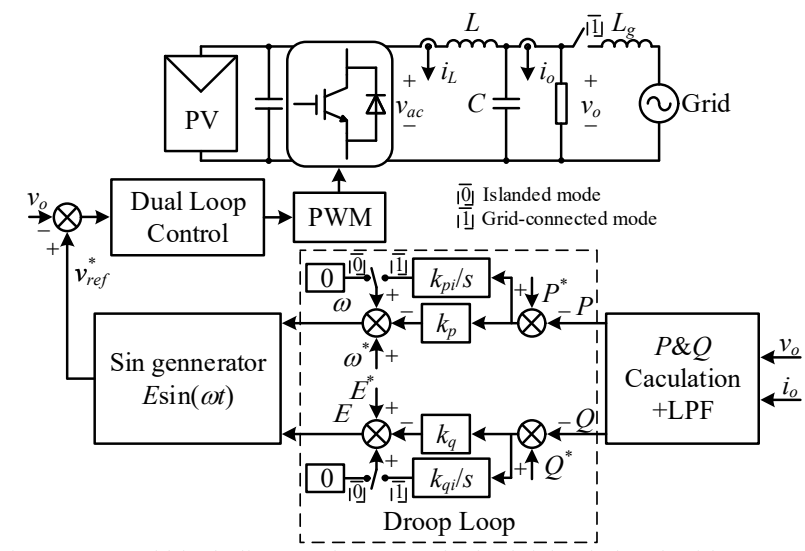

Fig. 1. Control block diagram from $[25]$ for both islanded and grid-connected modes. 
- Ideally, each transfer between operating modes should happen as a transient event triggered by changes of the demanded power references $P^{*}$ and $Q^{*}$. But, for the scheme in Fig. 1, an extra event has been caused by the insertion or removal of integral terms, whose influences depend on their initial values.

- When crossing from islanded to grid-connected mode, it is important to synchronize the phase of reference $v_{\text {ref }}^{*}$ in Fig. 1 with the grid voltage. Any inaccuracy may cause sudden current surge at the instant of the transfer.

\section{B. Technique from [26]}

The technique from [26] has been drawn in Fig. 2, where the rear inverter is again droop-controlled using (1) and (2) when islanded. It is then followed by a double-loop controller for tracking the demanded voltage reference. The chosen voltage controller may be a proportional-resonant (PR) or another controller with an ideally infinite gain at its tuned ac frequency. The dc-link voltage $V_{D C}$ is then controlled by the front boost controller using a proportional-integral (PI) or another controller with an ideally infinite dc gain. These control targets are swopped upon tied to the grid, where the rear inverter now regulates $V_{D C}$, while the front converter tracks maximum power that can be delivered by the source.

Mode transfer in this case is hence not a simple transient event with only changes of the reference values. It demands changes of controllers to meet the different control targets,

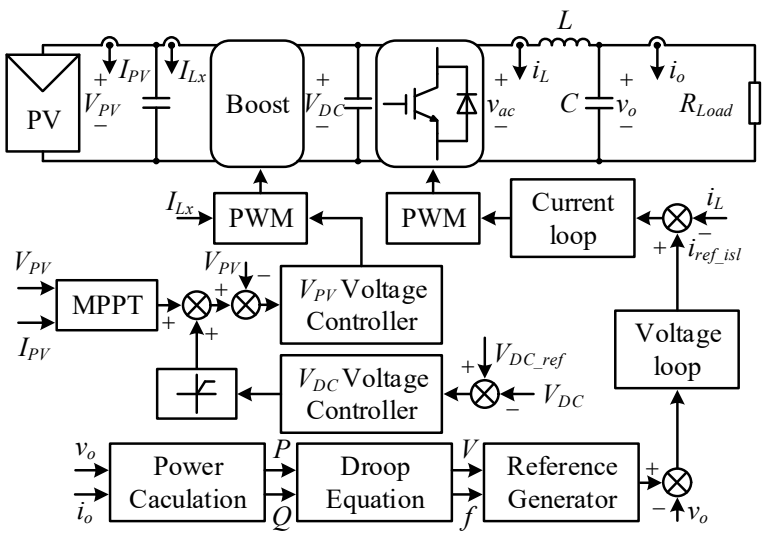

(a)

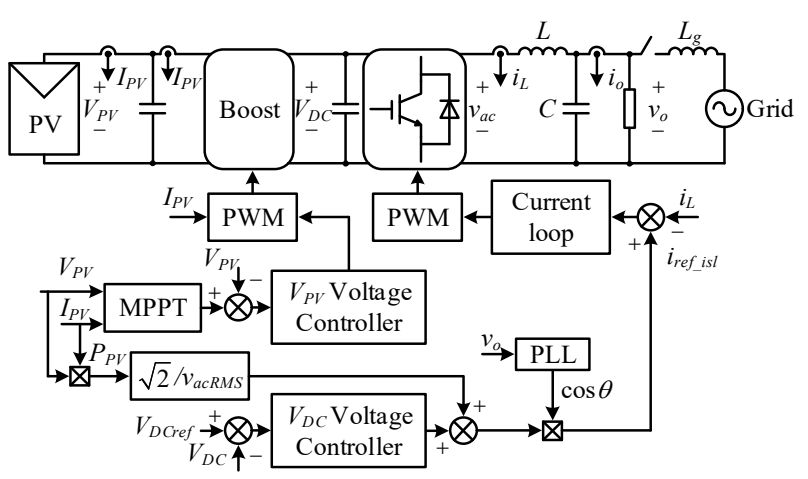

(b)

Fig. 2. Control block diagrams from [26] for (a) islanded and (b) grid-connected modes. whose impacts may be minimized by equalizing final conditions of the outgoing mode and initial conditions of the incoming mode. However, this equalization may be tough to realize accurately. An alternative technique with no abrupt changes of controllers may hence be preferred, and it is proposed in the next section.

\section{TRANSFER SCHEME With UNIFIED CONTROL CORE}

One objective of the proposed scheme is to apply equally well to multiple paralleled systems, including the two-system configuration shown in Fig. 3(a), where the two DGs are connected to the same point of common coupling (PCC). In islanded mode, the static switch (SS) switches off and the two DGs supply power to the local load. In grid-connected mode, the SS switches on and each DG maximizes its power generation to the local load and grid. Ideally, the SS should not be replaced by an electromechanical switch, whose transitional time is usually much longer. This transitional time is an internal feature of the electromechanical switch, and hence cannot be modified by the control schemes of the DGs. Furthermore, although the sources indicated in Fig. 3(a) are PVs, there are no restrictions to change them to other sources. Irrespective of that, they may be controlled by the schemes described below for both islanded and grid-connected modes.

\section{A. Islanded Mode}

Before progressing forwards, it is helpful to emphasize the essence of droop equations (1) and (2), which is to establish the one-to-one relationships between $\omega$ and $P$, and $E$ and $Q$ in the steady state. In other words, measurement of a certain $P$ will always correspond to only one value for $\omega$, and vice versa. With this in mind, a control scheme for each two-stage system in Fig. 3(a) when islanded has been developed according to Fig. 4(a), whose droop expressions have undergone two alterations. The

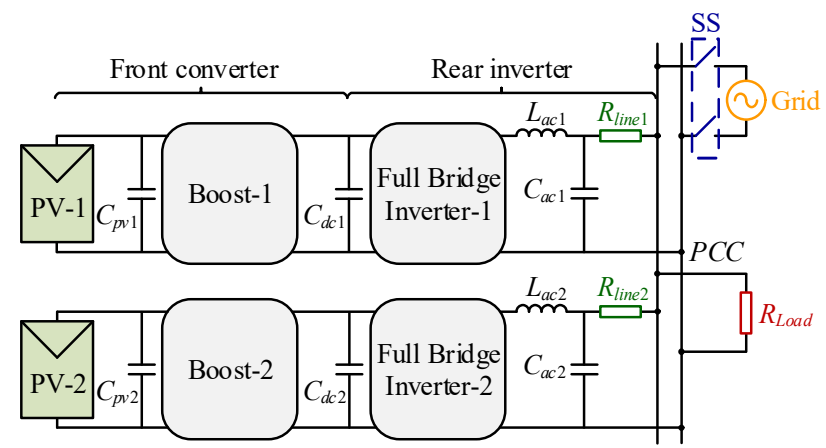

(a)

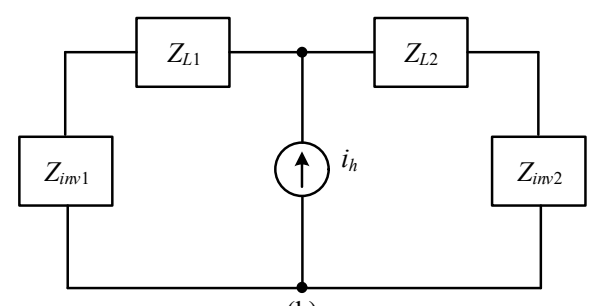

(b)

Fig. 3. Overview of (a) tested configuration and (b) its simplified equivalence at a harmonic frequency. 
first results in (3) and (4), whose variables have been re-notated to match those used in Fig. 4(a), and whose $\omega_{n}$ and $V_{n}$ have been swapped to better adapt to usually more resistive distribution feeders [29]. This swapping is irrespective of how the droop equations in (3) and (4) have been implemented.

$$
\begin{gathered}
V_{n}=V_{0 n}-k_{p n}\left(P_{P V r e f n}-P_{0 n}\right) \\
\omega_{n}=\omega_{0 n}-k_{q n}\left(Q_{0 n}-Q_{n}\right)
\end{gathered}
$$

where $P_{P V r e f n}$ and $\omega_{n}$ are desired power and angular frequency references of system $n, V_{n}$ and $Q_{n}$ are its measured root mean square value of output voltage and calculated reactive power, and $P_{0 n}, \omega_{0 n}, V_{0 n}$ and $Q_{0 n}$ are their respective rated values. Note too that subscript $n$ has been added to the droop coefficients $k_{p n}$ and $k_{q n}$ for distinguishing among the paralleled systems.

Additionally, it should be mentioned that virtual impedance may be added to the distribution feeder to bias it to be more inductive, so that droop equations from (1) and (2) can continue to be used. This has however not been done here. Explanation for that may be deduced from [30], where typical $R / X$ ratio of a low voltage (LV) line has been given as 7.7 , as compared to 0.85 of a medium voltage (MV) line and 0.31 of a high voltage (HV) line. Absolute $\Omega / \mathrm{km}$ of the LV line is also several times larger than those of the MV and HV lines. In other words, to virtually obtain an inductive LV line, the amount of virtual reactance needed may be sizable. This may reduce terminal voltage of the inverter much lower than the minimum voltage value from the droop controller at full load. Rising this minimum or narrowing the voltage droop range even further may be an option, but it depends on the resolution of the microprocessor used for implementing the scheme.

Another method for obtaining an inductive LV line is to

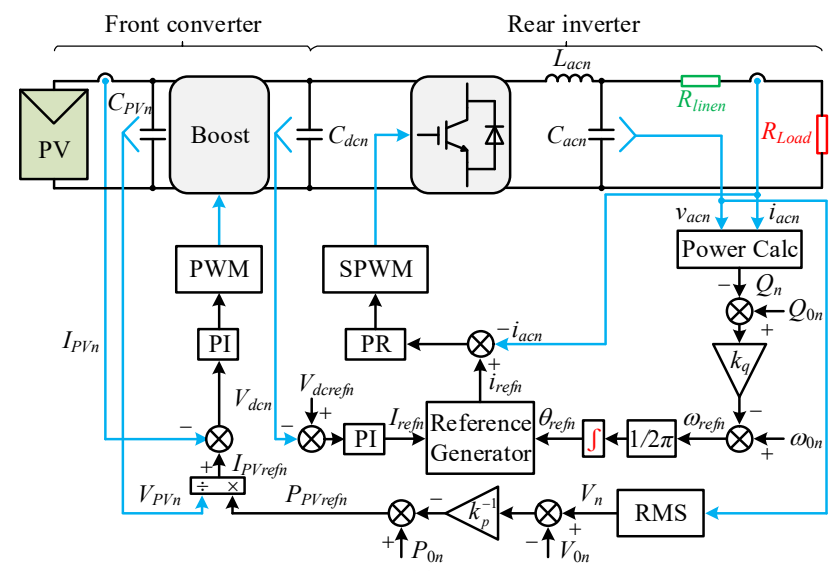

(a)

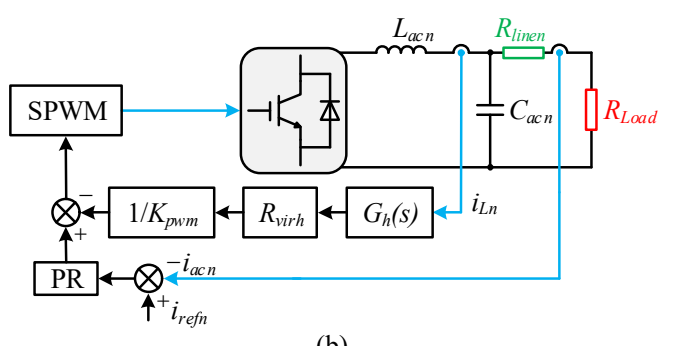

(b)

Fig. 4. Illustration of (a) proposed control scheme in islanded mode and (b) a method for inserting harmonic virtual resistance or impedance. insert a negative virtual resistance [31], which may have the risk of arriving at a negative overall resistance in case of accidental over-insertion. Because of this, (3) and (4) are used instead of (1) and (2). The second alteration applied to the chosen droop equations is then to rewrite (3) into (5), while keeping (4) unchanged.

$$
P_{P V \text { ref } n}=P_{0 n}-k_{p n}^{-1}\left(V_{n}-V_{0 n}\right)
$$

The ac output voltage $v_{a c n}$ in Fig. 4(a) should hence be measured with its magnitude $V_{n}$ substituted to (5) to obtain the desired power reference $P_{P V r e f n}$. However, this reference is not tracked by the rear inverter. Instead, it is divided by the measured source voltage $V_{P V n}$ to obtain a source current reference $I_{P V \text { refn }}$ for tracking by the front boost converter using a PI controller. Regulation of the intermediate dc-link voltage $V_{d c n}$ to follow its reference $V_{d c r e f n}$ is then performed by the rear inverter using a second PI controller to yield an output current amplitude $I_{r e f n}$ for the rear inverter. For a single-phase grid, a trap filter tuned at twice the line frequency may also be added for removing instantaneous oscillating ripple from the measured $V_{d c n}$, even though it has not been explicitly indicated in Fig. 4(a). Regardless of that, it can be summarized that the front boost converter regulates power flow and the rear inverter regulates the dc-link voltage when in the islanded mode. These control targets remain unchanged when switched to the grid-connected mode, as explained later. Smoother seamless transfer may hence be better ensured.

Moreover, using the outer dc-link voltage loop to regulate the inner output current loop may have an advantage. To explain, DG1 in Fig. 3(a) may be assumed to experience a small power disturbance. There may then be power exchange between DG1 and entities connected to the islanded grid. In most cases, the dc-link capacitor of DG1 with enough short-term energy storage will react faster than the primary source of DG1 and the distant DG2. Employing the dc-link voltage for regulating the output current may hence better match this physical reasoning.

The power amplitude obtained from (5) is subsequently converted into a sinusoidal current reference $i_{\text {refn }}$, whose phase angle $\theta_{\text {refn }}$ is integrated from $\omega_{\text {refn } n}$. Frequency $\omega_{r e f n}$ is, in turn, obtained from the droop expression in (4), after computing $Q_{0 n}$ from the measured output voltage $v_{a c n}$ and current $i_{a c n}$. Reference $i_{\text {refn }}$ is then tracked by output ac current $i_{a c n}$ in an inner current loop with a PR controller. The main features of the islanded scheme in Fig. 4(a) can thus be summarized, as follows.

- Power from the source is directly regulated by the immediate front converter, rather than by the rear inverter.

- Output current flowing to the load is directly regulated by the rear inverter, which also regulates the dc-link voltage.

\section{B. Grid-Connected Mode}

After connected to the grid, the focus of each system is to maximize its power generation, rather than to share local load demands with others. Those droop equations in (4) and (5) are hence no longer necessary. Instead, the source current reference $I_{P V \text { refn }}$ in Fig. 5 is now obtained from a maximum-power-point (MPP) tracker with $V_{P V n}$ and $I_{P V n}$ of the source being its inputs. 
This reference is then tracked by $I_{P V n}$ using the same PI controller and front converter, when islanded. That leaves the rear inverter to regulate the dc-link voltage $V_{d c n}$ using the same PI controller, where the output $I_{\text {refn }}$ is the grid current magnitude that will channel the source power to the grid, after deducting power losses. This magnitude, together with angle $\theta_{\text {refn }}=\theta_{\text {grid }}$ from a PLL, is then converted to a sinusoidal reference $i_{\text {refn }}$ for tracking the output grid current using the same PR controller. Features of the grid-connected scheme in Fig. 5 can hence be summarized as follows.

- Maximum power from the source is directly regulated by the immediate front converter.

- Output current flowing to the grid and dc-link voltage are directly regulated by the rear inverter. This allows the grid current to continue being sinusoidal, even in the presence of grid voltage harmonics.

\section{Seamless Transfer}

Transfers between operating modes shown in Fig. 4(a) and Fig. 5 are generally seamless because of the following reasons, which may be compared with features of existing schemes summarized in Section II.

- Power generated by the source is always regulated by the immediate front converter using the same PI controller fed with current reference $I_{P V r e f n}$.

- Output load or grid current is, in turn, always regulated by the inner loop of the rear inverter using the same PR controller with $i_{\text {refn }}$ as a reference. The dc-link voltage is also always regulated by the same PI controller with $V_{d c r e f n}$ as a reference.

It is thus appropriate to conclude that the control core and targets have been unified with each transfer merely characterized by two changes of references. The first involves changing the power reference (through current reference $I_{P V r e f n}$ ) between values computed by (5) and the MPP tracker of the PV system. The second demands a change of reference phase angle $\theta_{\text {refn }}$ between values computed by (4) and the grid-synchronized PLL. The change of $\theta_{\text {refn }}$ from islanded to grid-connected mode is particularly less disturbing here, since the proposed scheme in Fig. 5 uses $\theta_{\text {refn }}=\theta_{\text {grid }}$ to create reference $i_{\text {refn }}$ for tracking by the output grid current $i_{a c n}$. Any inaccuracy with grid synchronization at the instant of transfer will hence merely result in a different power factor angle, rather than a surge in current as with voltage regulation.

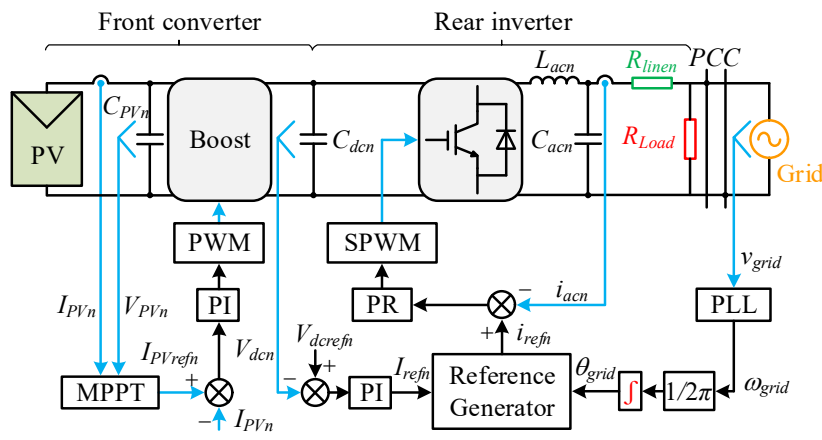

Fig. 5. Illustration of control scheme in grid-connected mode.
During the reverse grid-connected to islanded transfer, the incoming islanded scheme in Fig. 4(a) will also operate smoothly with each DG regulated to provide an appropriate terminal voltage. This ability can be explained by referring to Fig. 4(a), where droop equation (5) can be seen to provide an outermost voltage control loop. This loop uses a proportional feedback controller with gain $k_{p n}^{-1}$. At the instant of transfer, this proportional controller acts on an error computed from the fixed (rated) voltage reference $V_{0 n}$ and measured amplitude of the output voltage $v_{a c n}$, which also is the voltage across capacitor $C_{a c n}$. Its value is thus always continuous with no step change occurring even at the instant of transfer. Proper provision of an output voltage amplitude that always stays within the desired narrow droop range is thus ensured. As for droop equation (4), it behaves like a PLL, whose function is to generate angular frequency $\omega_{n}$ for obtaining an ac signal from its amplitude (or performing synchronous frame transformation in some existing schemes). Realization of (4) and (5) as proportional feedback controllers can thus always ensure that steady-state operating point of the DG stays on the two linear droop lines upon entering the incoming islanded mode.

\section{Harmonic Load Sharing}

Nonlinear loads are now quite common, and when in the islanded mode, the two DGs in Fig. 3(a) are usually required to share them equally. Sharing principle of the two DGs can be explained with the simplified harmonic diagram shown in Fig. 3(b) when in the islanded mode [31]. In the diagram, the common middle harmonic source is for representing the nonlinear loads, whose current division between the two DGs may be controlled. For that, methods from [32] and [33] may be evaluated, even though the former is originally introduced for harmonic damping, rather than harmonic sharing between DGs when in the islanded mode. The first method relies on extracting harmonic voltage as its control input, while the second method depends on the extraction of harmonic current.

Despite those differences, their common intention is to emulate each DG as a virtual resistance at the harmonic frequency of interest. This emulation may be explained with the second method illustrated in Fig. 4(b). As seen, harmonic current through $L_{a c n}$ is first measured and extracted using $G_{h}(s)$. Alternatively, harmonics of $i_{a c n}$ may be extracted instead, since harmonic current through $C_{a c n}$ is comparably much smaller and $i_{a c n}$ has already been measured for feedback. The extracted harmonic current is then multiplied with a virtual resistance $R_{\text {virh }}$ and a scaling gain $1 / K_{\text {pwm }}$ for modulation. The resulting signal is a harmonic modulating reference for controlling the immediate terminal voltage of the converter. Equivalently, it thus resembles a virtual resistance $R_{\text {virh }}$ inserted in series with the line at the desired harmonic frequency. Rightfully, $L_{a c n}$ is in series too, but at switching frequencies commonly adopted in practice, its value is not prominent and hence not explicitly shown in Fig. 3(b). By sizing $R_{\text {virh }}$ appropriately for each DG, division of harmonic load current based on impedance ratio may then be ensured [33].

The method may also be retained when in the grid-connected mode, but with a slightly different set of control targets. The 
first target is to control the DG to divert most of the local nonlinear load harmonics away from the grid, since it is not likely to expect the grid to supply or sink large amount of local harmonic current. Retaining the virtual insertion method may therefore provide a means to do so through adjusting $R_{\text {virh }}$ to be much smaller than the grid impedance. In addition, for a distribution line with nonlinear loads and a distorted grid, the main issue pointed out in [32] is harmonic voltage propagation and amplification. The solution found in [32] is to terminate the line with a shunt active filter and control it to behave like a small damping resistance. The second target is thus to provide this damping, which can be done by the unified control core, so long as the virtual resistance insertion scheme is retained.

\section{Small-Signal Modelling Stability Analysis}

Analysis can now be performed with the islanded scheme in Fig. 4(a), where only the active-power droop equation has been inverted from (3) to (5). Analysis of the grid-connected scheme in Fig. 5 is however not explicitly demonstrated here, since it involves usual MPP tracking and dc-link voltage regulation. Moreover, if preferred, the two-system configuration shown in Fig. 3(a) may be simplified to the equivalent circuit shown in Fig. 6, before beginning with the islanded analysis.

\section{A. Models of System}

From the dc-link voltage loop, the reference amplitude $I_{\text {refn }}$ for the output current can be expressed as:

$$
I_{r e f n}=\left(k_{p p}+\frac{k_{i i}}{s}\right)\left(V_{d c r e f n}-V_{d c n}\right)
$$

where $k_{p p}$ and $k_{i i}$ are proportional and integral gains, respectively. Moreover, by noting that the net change of energy at the dc-link is equal to the difference in energy flowing through the front converter and rear inverter, the resulting energy-balance expression can be written as:

$$
\int P_{p v n}(t) \mathrm{d} t-\int P_{n}(t) \mathrm{d} t=\frac{1}{2} C_{d c n} V_{d c n}^{2}-\frac{1}{2} C_{d c n} V_{d c r e f n}^{2}
$$

Equations (4) to (7) then give the following state equation for a single PV system.

$$
\left[\begin{array}{l}
\Delta \dot{V}_{d c n} \\
\Delta \dot{\omega}_{n} \\
\Delta \dot{I}_{d n} \\
\Delta \dot{I}_{q n}
\end{array}\right]=\left[A_{n}\right]\left[\begin{array}{l}
\Delta V_{d c n} \\
\Delta \omega_{n} \\
\Delta I_{d n} \\
\Delta I_{q n}
\end{array}\right]+\left[B_{n}\right]\left[\Delta V_{n}\right]+\left[C_{n}\right]\left[\begin{array}{c}
\Delta P_{n} \\
\Delta Q_{n}
\end{array}\right]
$$

where

$m_{d n}=-I_{q n} / I_{d n}^{2}+I_{q n}^{2}, m_{q n}=I_{d n} / I_{d n}^{2}+I_{q n}^{2}, n_{d n}=I_{d n} / \sqrt{I_{d n}^{2}+I_{q n}^{2}}$ and $n_{q n}=I_{q n} / \sqrt{I_{d n}^{2}+I_{q n}^{2}}, k_{d c}=1 / C_{d c n} V_{d c n}$,

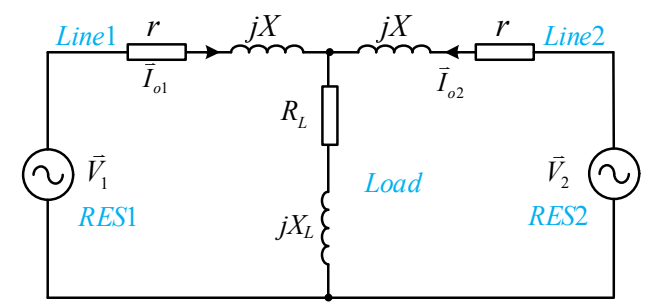

Fig. 6. Equivalent circuit of two paralleled systems shown in Fig. 3(a).

$$
\begin{gathered}
{\left[A_{n}\right]=\left[\begin{array}{cccc}
0 & 0 & 0 & 0 \\
0 & -\omega_{f} & 0 & 0 \\
\frac{k_{i i} m_{q n}}{m_{d n} n_{q n}-m_{q n} n_{d n}} & \frac{n_{q n}}{m_{d n} n_{q n}-m_{q n} n_{d n}} & 0 & 0 \\
\frac{k_{i i} m_{d n}}{m_{q n} n_{d n}-m_{d n} n_{q n}} & \frac{n_{d n}}{m_{q n} n_{d n}-m_{d n} n_{q n}} & 0 & 0
\end{array}\right],} \\
{\left[B_{n}\right]=\left[\begin{array}{c}
-k_{d c} k_{p}^{-1} \\
0 \\
\frac{-k_{p p} k_{d c} k_{p}^{-1} m_{q n}}{m_{d n} n_{q n}-m_{q n} n_{d n}} \\
\frac{-k_{p p} k_{d c} k_{p}^{-1} m_{d n}}{m_{q n} n_{d n}-m_{d n} n_{q n}}
\end{array}\right],\left[\begin{array}{cc}
-k_{d c} & 0 \\
0 & k_{q} \omega_{f} \\
\frac{-k_{p p} k_{d c} m_{q n}}{m_{d n} n_{q n}-m_{q n} n_{d n}} & 0 \\
\frac{-k_{p p} k_{d c} m_{d n}}{m_{q n} n_{d n}-m_{d n} n_{q n}} & 0
\end{array}\right] .}
\end{gathered}
$$

For two paralleled systems, the state equation changes to:

$$
\begin{gathered}
{\left[\begin{array}{l}
\Delta \dot{X}_{1} \\
\Delta \dot{X}_{2}
\end{array}\right]=[T]\left[\begin{array}{l}
\Delta X_{1} \\
\Delta X_{2}
\end{array}\right]} \\
\text { where } A=\left[\begin{array}{cc}
A_{1} & 0 \\
0 & A_{2}
\end{array}\right], B=[A]+([B][D][E]+[C]([I][Z]+[U]))[K]
\end{gathered}
$$

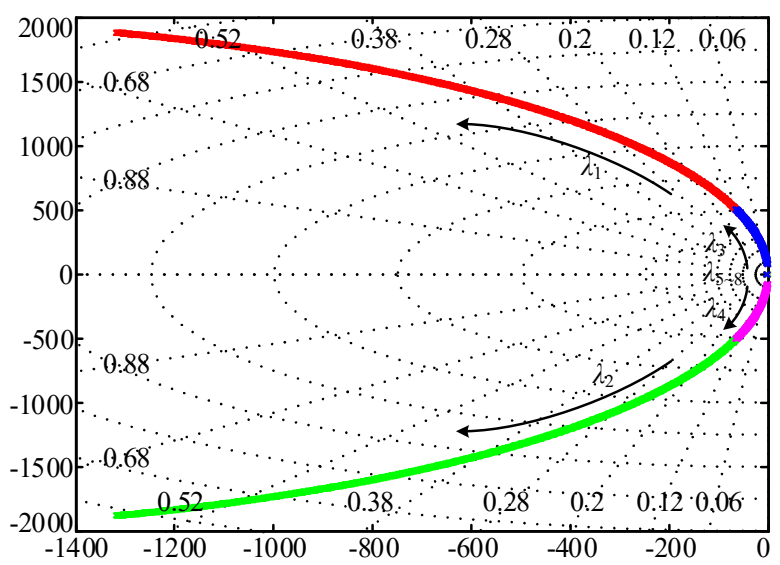

Fig. 7. Root loci plotted with $1 \leq k_{p}^{-1} \leq 1000$.

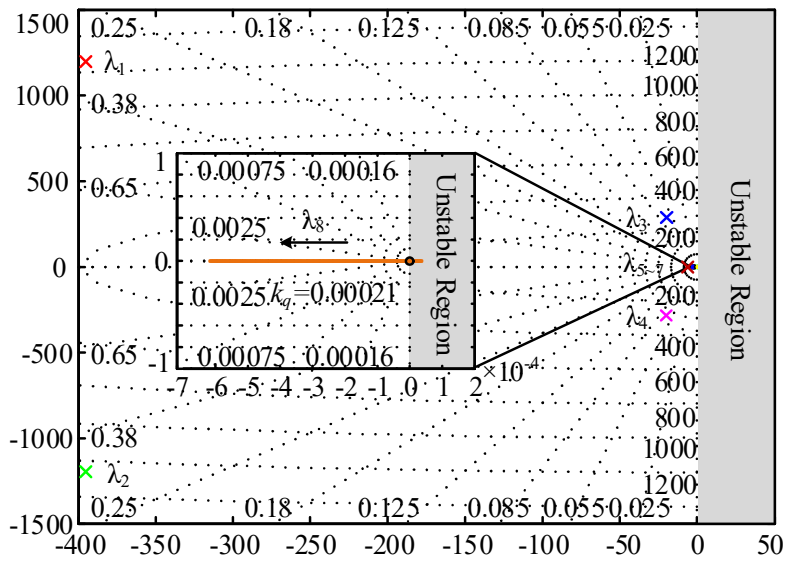

Fig. 8. Root loci plotted with $0.0001 \leq k_{q} \leq 0.002$. 
$[K]=\left[\begin{array}{llllllll}0 & 0 & 1 & 0 & 0 & 0 & 0 & 0 \\ 0 & 0 & 0 & 1 & 0 & 0 & 0 & 0 \\ 0 & 0 & 0 & 0 & 0 & 0 & 1 & 0 \\ 0 & 0 & 0 & 0 & 0 & 0 & 0 & 1\end{array}\right]$.

More details related to small-signal modeling can be found in [29], where the same procedure has been applied to a different control scheme.

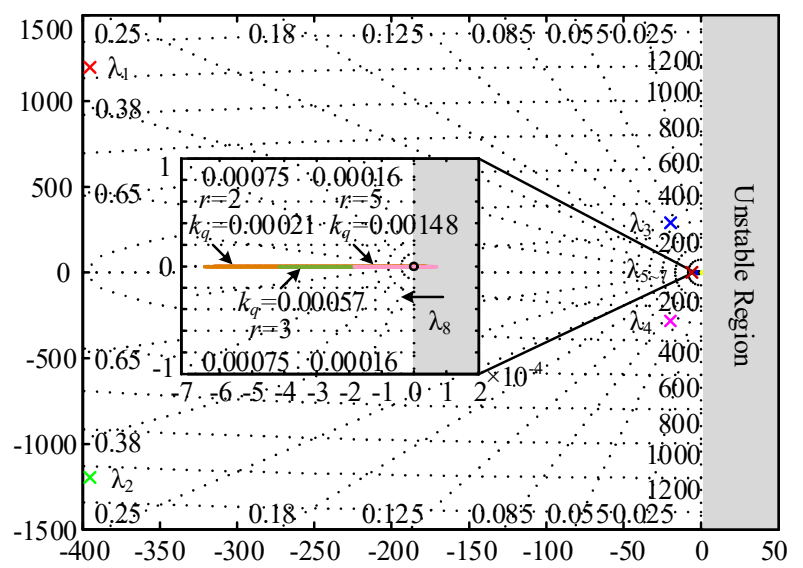

(a)

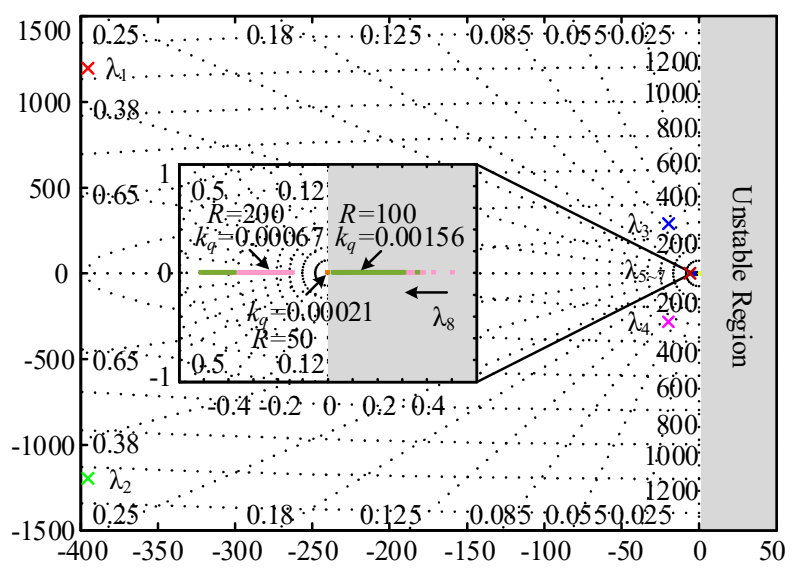

(b)

Fig. 9. Root loci plotted for $0.0001 \leq k_{q} \leq 0.002$ with different (a) active values of distribution lines and (b) resistive values of load.

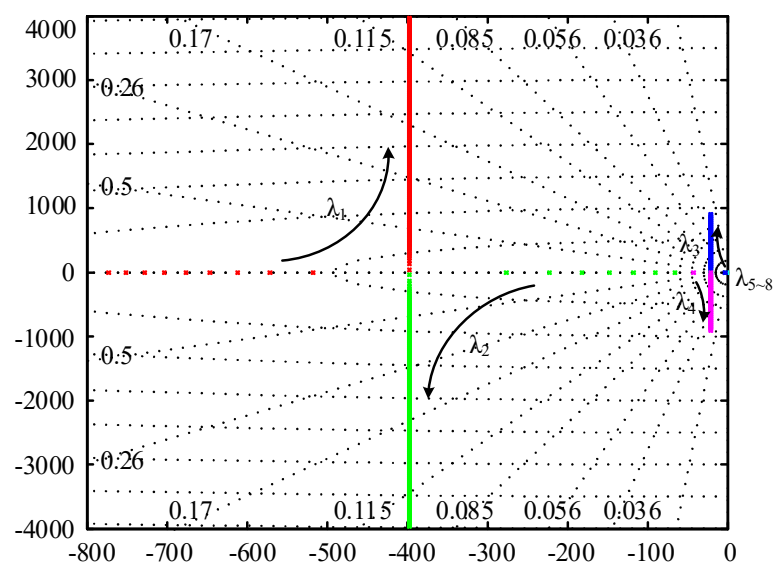

Fig. 10. Root loci plotted with $-100 \leq k_{i i} \leq-0.1$.

\section{B. Eigenvalue Analysis}

Using (10) and the variable notations marked in Fig. 6, a root loci can be plotted to analyze the response when $\vec{V}_{1}=\vec{V}_{2}=218+j 30 \mathrm{~V}$ for the two systems, $Z_{\text {line }}=r+j X=2+$ $j 0.2 \Omega$ for the distribution lines, $Z_{L}=R_{L}+j X_{L}=50+j 0.2 \Omega$ for the load, and $\omega_{f}=3.141 \mathrm{rad} / \mathrm{s}$ as the cut-off frequency for low-pass filtering out the average powers. Fig. 7 shows the obtained root loci with $k_{q}=0.001, k_{p p}=-0.005, k_{i i}=-10$, and $k_{p}^{-1}$ varying from 1 to 1000 (subscript $n$ in (4) and (5) has been

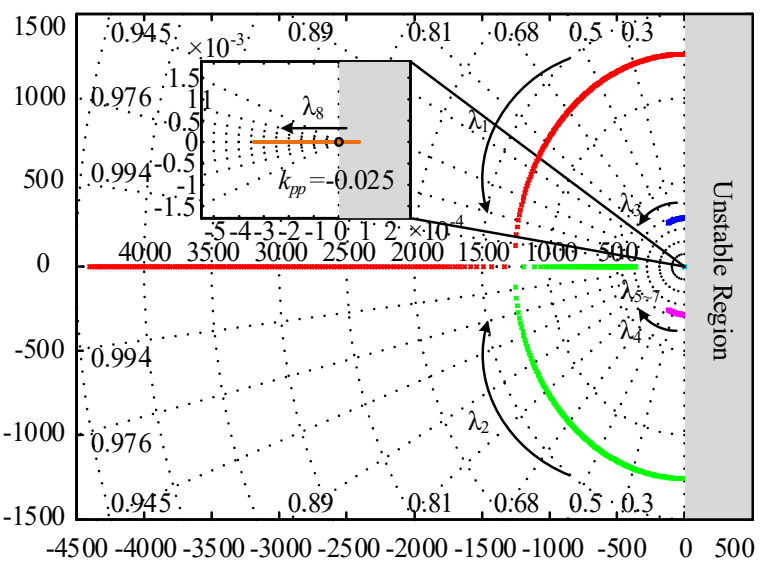

Fig. 11. Root loci plotted with $-0.03 \leq k_{p p} \leq-0.0001$.

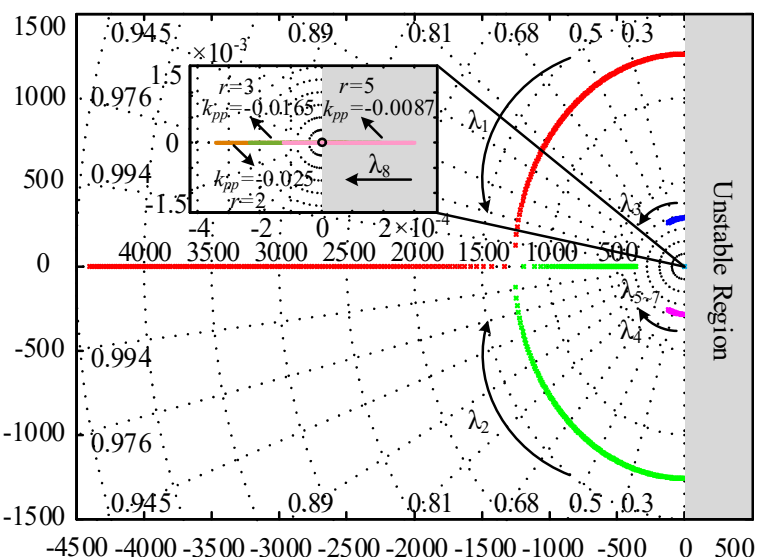

(a)

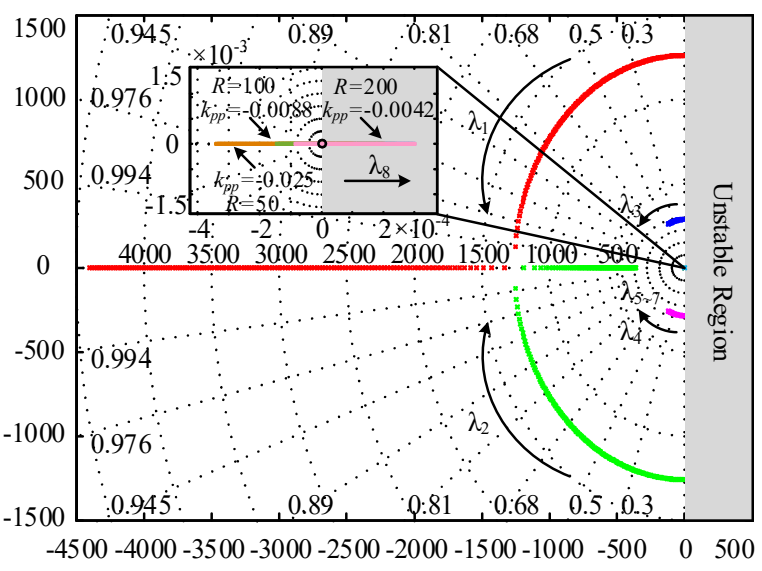

(b)

Fig. 12. Root loci plotted for $-0.03 \leq k_{p p} \leq-0.0001$ with different (a) active values of distribution lines and (b) resistive values of load. 
dropped for conciseness). The immediate observation is that the poles $\lambda_{1 \sim 4}$ are far away from the real axis as $k_{p}^{-1}$ increases, while the others $\lambda_{5 \sim 8}$ are close to the imaginary axis. The combined effect is thus an improvement of the system overshoot. Regardless of that, the overall system is stable, since all poles are in the left-half $s$-plane. Therefore, the main considerations here should be the desired output voltage range of the rear inverter and dynamic response of the overall system. These considerations lead to $k_{p}^{-1}=300$ being chosen.

A second set of root loci with $k_{p}^{-1}=300, k_{p p}=-0.005, k_{i i}=-10$, and $k_{q}$ varying from 0.0001 to 0.002 can then be plotted in Fig. 8 , from which it can be seen that the dominant pole $\lambda_{8}$ enters the right-half s-plane from $k_{q} \leq 0.00021$ onwards. This instability crossing point of $k_{q}$ changes with the line and load impedance as demonstrated in Fig. 9. Specifically, the root loci in Fig. 9(a) shows that as active component $r$ of the distribution lines increases, stable range of $k_{q}$ decreases. Similarly, as shown in Fig. 9(b), by increasing resistive component $R_{L}$ of the load, the crossing point of $k_{q}$ moves from 0.00021 to 0.00156 , and then to 0.00067 .

The next set of root loci has then been plotted in Fig. 10 with $k_{p}^{-1}=300, k_{q}=0.001, k_{p p}=-0.005$, and $k_{i i}$ varying from -0.1 to -100 . Despite the variation, the dominant poles $\lambda_{1}$ and $\lambda_{2}$, and other further poles are found to remain in the left-half s-plane. The system is thus always stable. The same observation may also be deduced from Fig. 11, where a decrease of $k_{p p}$ from -0.0001 to -0.03 with $k_{p}^{-1}=300, k_{q}=0.001$ and $k_{i i}=-10$ has caused dominant pole $\lambda_{8}$ to move closer to the imaginary axis. It eventually becomes unstable as $k_{p p}$ falls under -0.025 . This instability crossing point of $k_{p p}$ can similarly be changed by varying the line and load impedances, as demonstrated in Fig. 12. More precisely, the unstable range of $k_{p p}$ will increase with larger active component $r$ of the distribution lines as in Fig. 12(a) and with larger resistive component $R_{L}$ of the load as in Fig. 12(b)

\section{Simulation Results}

Simulations have been performed with two similarly rated PV systems in MATLAB/Simulink. Parameters used are given in Table I for each system, which are also the values that have been used experimentally. The main purpose of the simulations is to verify the anticipated seamless transfer between grid-connected and islanded modes, before performing similar

TABLE I

PARAMETERS USED FOR TESTING

\begin{tabular}{ll}
\hline \hline \multicolumn{1}{c}{ Parameter } & Values \\
\hline PV panel voltage variation $\left(V_{P V n}\right)$ & $280 \mathrm{~V}-350 \mathrm{~V}$ \\
Rated output voltage amplitude $\left(V_{0 n}\right)$ & $220 \mathrm{~V}(\mathrm{rms})$ \\
Rated frequency of the PV inverter $\left(f_{0 n}\right)$ & $50 \mathrm{~Hz}$ \\
DC-link reference voltage $\left(V_{d c r e f n}\right)$ & $400 \mathrm{~V}$ \\
DC-link voltage capacitance $\left(C_{d c n}\right)$ & $940 \mu \mathrm{F}$ \\
Output filter inductance $\left(L_{a c n}\right)$ & $4 \mathrm{mH}$ \\
Output filter capacitance $\left(C_{a c n}\right)$ & $5 \mu \mathrm{F}$ \\
Inverter switching frequency $\left(f_{s n}\right)$ & $10 \mathrm{kHz}$ \\
Active droop coefficient $\left(k_{p n}^{-1}\right)$ & $300(\mathrm{~s} \bullet \mathrm{W}) / \mathrm{V}$ \\
Reactive droop coefficient $\left(k_{q n}\right)$ & $0.001 \mathrm{rad} / \mathrm{Var}$ \\
\hline \hline
\end{tabular}

experiments. Simulation results are shown in Fig. 13 for the transfer from islanded to grid-connected mode and the reverse. Clearly, no major current surge or other disturbances have been observed from the waveforms, which to a great extent, have verified the anticipated seamless transfers brought by the proposed scheme. Other simulated features have also been found to match the experimental findings closely, and have hence been omitted here for conciseness. More details about the features can be found in the next section, where the

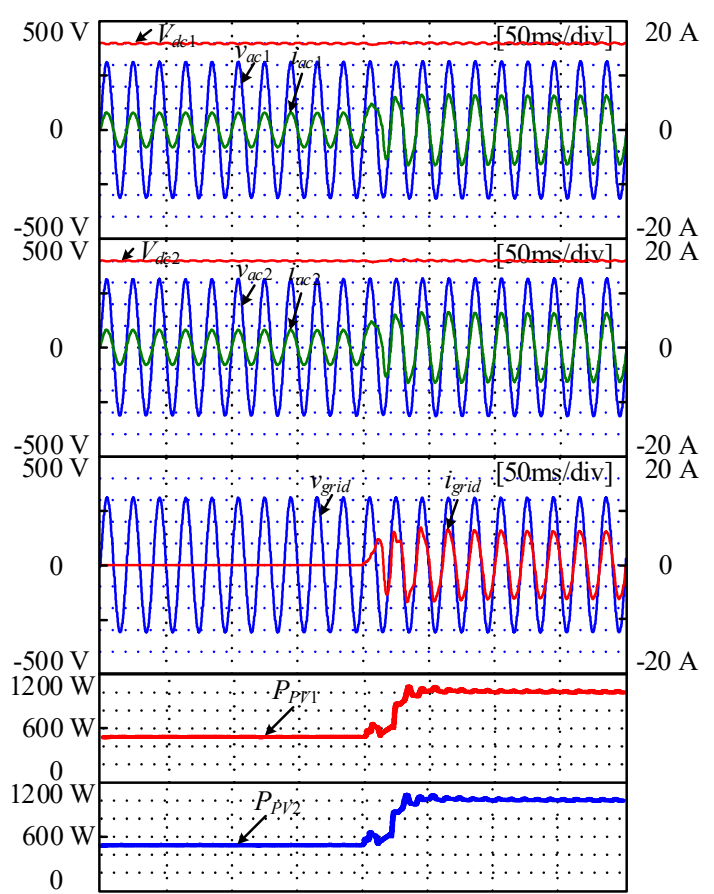

(a)

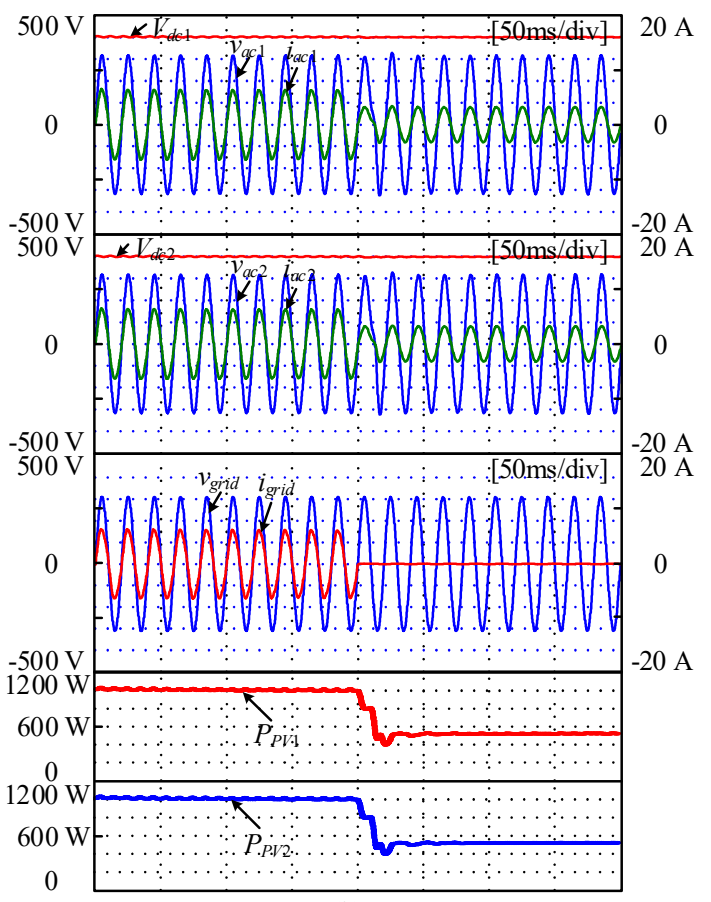

(b)

Fig. 13. Simulation of two systems (a) transfer from islanded to grid-connected mode, and (b) transfer from grid-connected to islanded mode. 
experimental results are described.

\section{EXPERIMENTAL RESULTS}

Using two TMS320F28335 digital signal processors, two paralleled $1.5 \mathrm{~kW}$ PV systems have been tested to verify the proposed seamless scheme with a unified control core. Sources for the two systems are from two Chroma 62150H-600S dc supplies, programmed to emulate typical PV characteristics. Fig. 14(a) shows the setup, while its parameters are given in Table I. Its islanded results are shown in Fig. 15, where both systems initially supply $724 \mathrm{~W}$ and $453 \mathrm{~W}$ separately to their

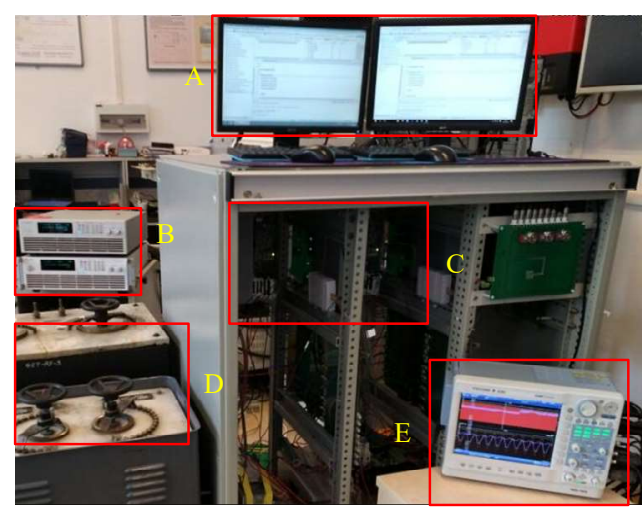

(a)

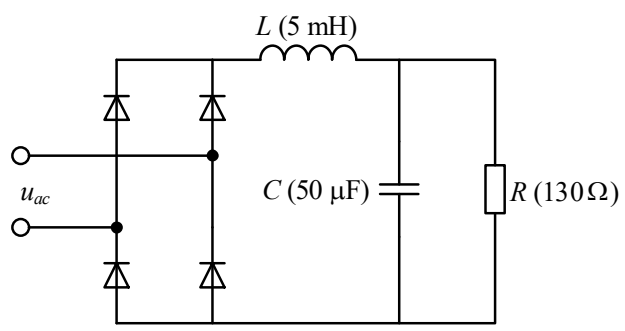

(b)

Fig. 14. Illustration of (a) laboratory setup: A - computers, B - dc sources, $\mathrm{C}$ - converters and inverters, D - loads, and E - YOKOGAWA DL850, and (b) nonlinear load used for testing.

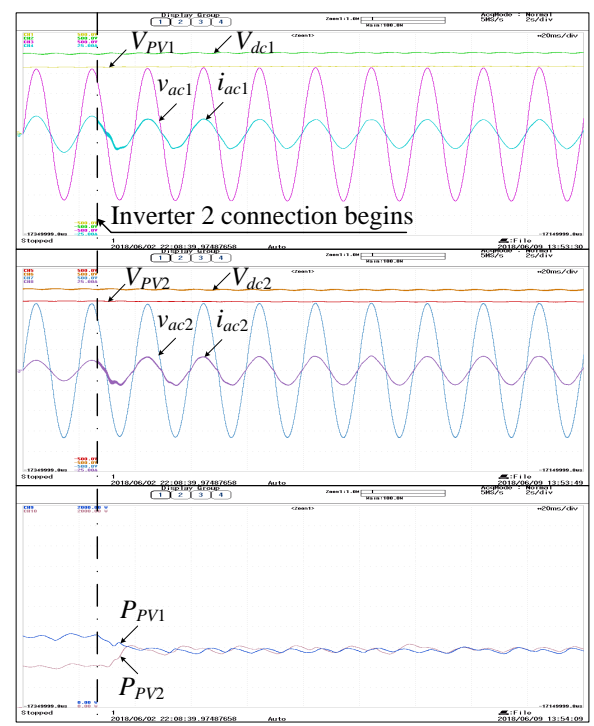

Fig. 15. Experimental results operating in islanded mode. respective loads (peak voltages $v_{a c 1}=322.7 \mathrm{~V}$ and $v_{a c 2}=331.0$ $\mathrm{V}$, and peak currents $i_{a c 1}=4.49 \mathrm{~A}$ and $i_{a c 2}=2.74 \mathrm{~A}$ ). Upon being interconnected at the instant marked by the dashed vertical line, the islanded results progress to show that power sharing has become more even with $P_{1}=591 \mathrm{~W}$ and $P_{2}=590$ $\mathrm{W}$, after two transient fundamental cycles (peak voltages $v_{a c 1}=$ $328.2 \mathrm{~V}$ and $v_{a c 2}=331.2 \mathrm{~V}$, and peak currents $i_{a c 1}=3.61 \mathrm{~A}$ and $i_{a c 2}=3.57 \mathrm{~A}$ ). During this time, terminal voltages of the two PV sources have also changed from $V_{P V 1}=331.5 \mathrm{~V}$ to $334.7 \mathrm{~V}$ and $V_{P V 2}=340.3 \mathrm{~V}$ to $336.2 \mathrm{~V}$, while keeping their respective dc-link voltages unchanged at $400 \mathrm{~V}$.

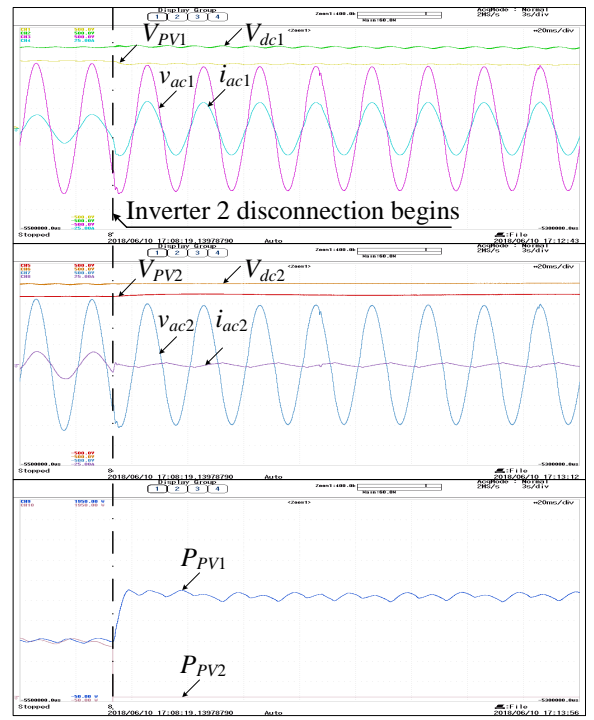

Fig. 16. Experimental results demonstrating disconnection of a system when operating in islanded mode.

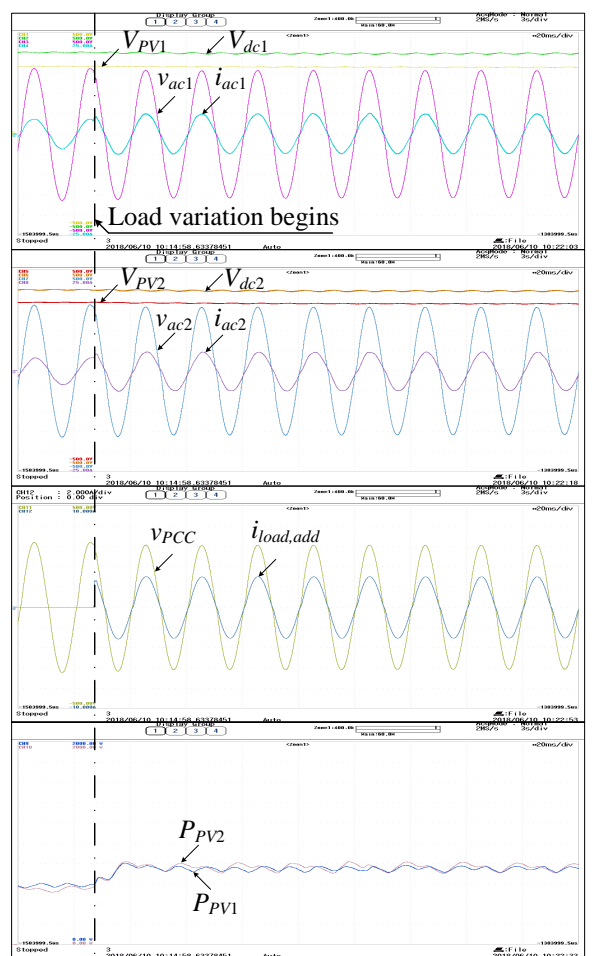

Fig. 17. Experimental results demonstrating load variation when operating in islanded mode. 
The proposed scheme can thus enforce equal load sharing when islanded, and can ride through sudden system or load changes. To illustrate this, the second PV system has been intentionally turned off in Fig. 16. This causes the first PV system to power the load alone with its ac output current increased from $3.52 \mathrm{~A}$ to $6.52 \mathrm{~A}$ and its output voltage $v_{a c 1}$ decreased from $322.9 \mathrm{~V}$ to $308.6 \mathrm{~V}$. Simultaneously, the terminal voltage of the first PV source drops from $335.9 \mathrm{~V}$ to $318.6 \mathrm{~V}$, while that of the second PV source rises from $337.2 \mathrm{~V}$ to near its open-circuit value of $343.6 \mathrm{~V}$. Again, these changes occur without affecting both dc-link voltages at $400 \mathrm{~V}$.

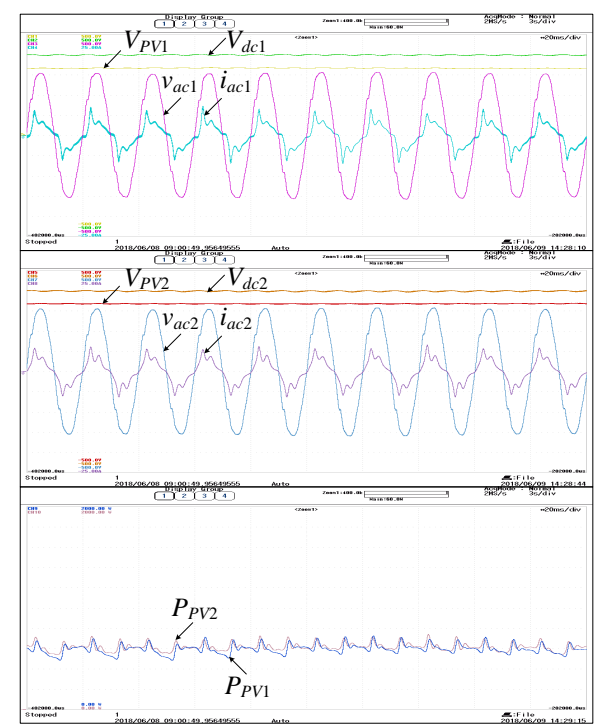

Fig. 18. Experimental results with non-linear load when operating in islanded mode.

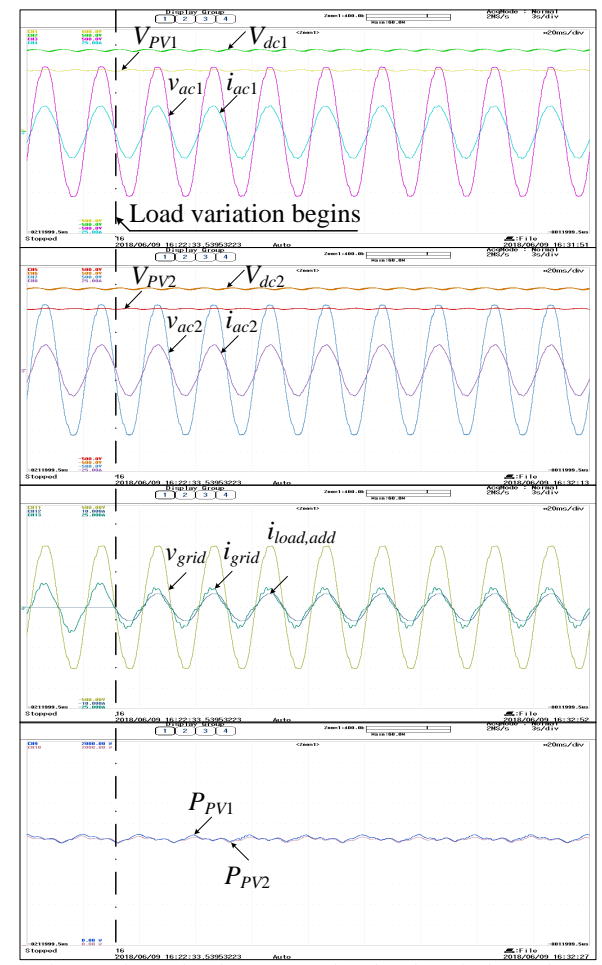

Fig. 19. Experimental results demonstrating load variation when connected to grid.
The same robustness has also been observed in Fig. 17, where output currents have increased from $i_{a c 1}=3.7$ A to 4.95 $\mathrm{A}$ and $i_{a c 2}=3.44 \mathrm{~A}$ to $4.79 \mathrm{~A}$ (output voltages have decreased from $v_{a c 1}=326.2 \mathrm{~V}$ to $313.2 \mathrm{~V}$ and $v_{a c 2}=329.5 \mathrm{~V}$ to $315.3 \mathrm{~V}$ ) to meet the larger islanded load. In the figure, $i_{\text {load,add }}$ represents the added load current, whose presence causes terminal

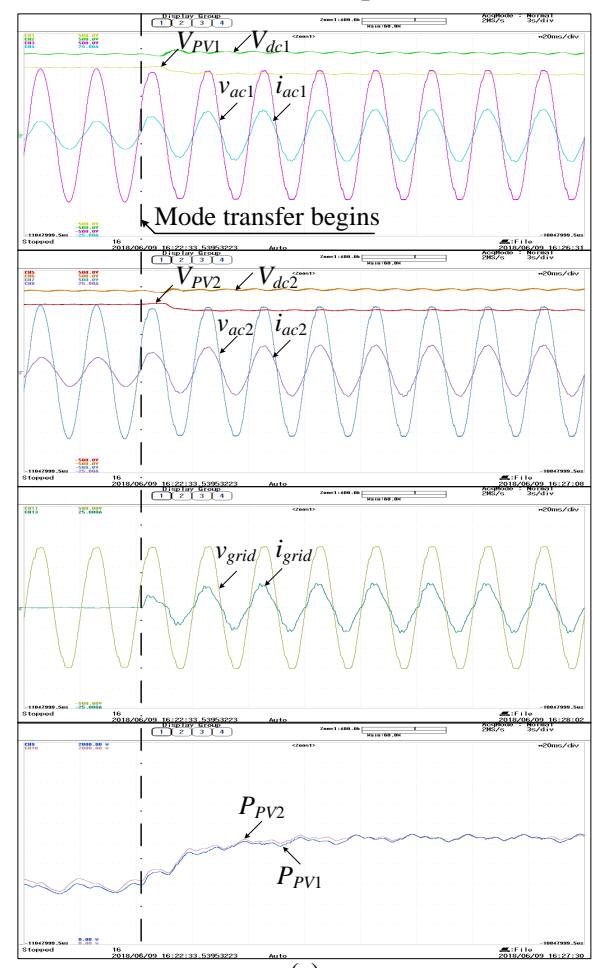

(a)

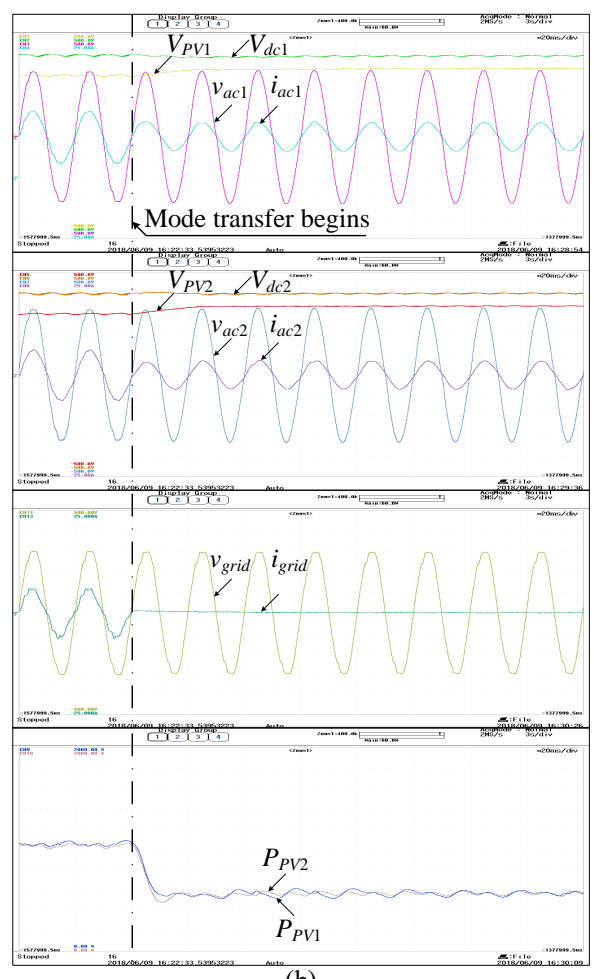

(b)

Fig. 20. Experimental results for (a) transfer from islanded to grid-connected mode, and (b) transfer from grid-connected to islanded mode. 
voltages of the two PV sources to change from $V_{P V 1}=334.2 \mathrm{~V}$ to $330.2 \mathrm{~V}$ and $V_{P V 2}=336.9 \mathrm{~V}$ to $331.7 \mathrm{~V}$ without affecting their respective dc-link voltages at $400 \mathrm{~V}$. These changes eventually result in very close $P_{1}=774 \mathrm{~W}$ and $P_{2}=755 \mathrm{~W}$, which certainly, are enforced by the droop expression in (5), when in the islanded mode.

Islanded experimental testing has next been performed with the nonlinear load shown in Fig. 14(b). Its results are given in Fig. 18, from which root mean square (RMS) and total harmonic distortion (THD) values of $v_{a c 1}$ are read as $226.8 \mathrm{~V}$ and $4.63 \%$, respectively. Corresponding values for $v_{a c 2}$ are $227.8 \mathrm{~V}$ and $4.41 \%$, respectively. As for currents, their RMS and THD values are $2.85 \mathrm{~A}$ and $41.98 \%$ for $i_{a c 1}$, and $2.90 \mathrm{~A}$ and $35.62 \%$ for $i_{a c 2}$. The RMS voltages and currents, and their power factors have then been used for computing active powers generated by the two DGs when in the islanded mode. Their values are $P_{1}=646 \mathrm{~W}$ and $P_{2}=661 \mathrm{~W}$. Power sharing has hence been reasonably enforced by the proposed islanded scheme in Fig. 4(a), even when supplying a nonlinear load.

On the other hand, when connected to the grid, Fig. 19 shows that an increase in load will not affect the terminal voltages of the two PV sources, and dc-link voltages and ac output currents of the two systems. Instead, the power injected to the grid drops from $P_{g}=882 \mathrm{~W}$ to $665 \mathrm{~W}$ (grid current $i_{\text {grid }}$ decreases from $i_{\text {grid }}$ $=5.63 \mathrm{~A}$ to $4.24 \mathrm{~A}$ ), so that more power can be channeled to meet the increase in load.

Fig. 20 shows the results when the system is transferred from islanded to grid-connected mode, and the reverse. The former in Fig. 20(a) shows the two systems supplying a local load of $1173 \mathrm{~W}\left(P_{1}=576 \mathrm{~W}\right.$ and $\left.P_{2}=597 \mathrm{~W}\right)$ before the transfer. After the transfer, the respective MPP trackers of both systems force

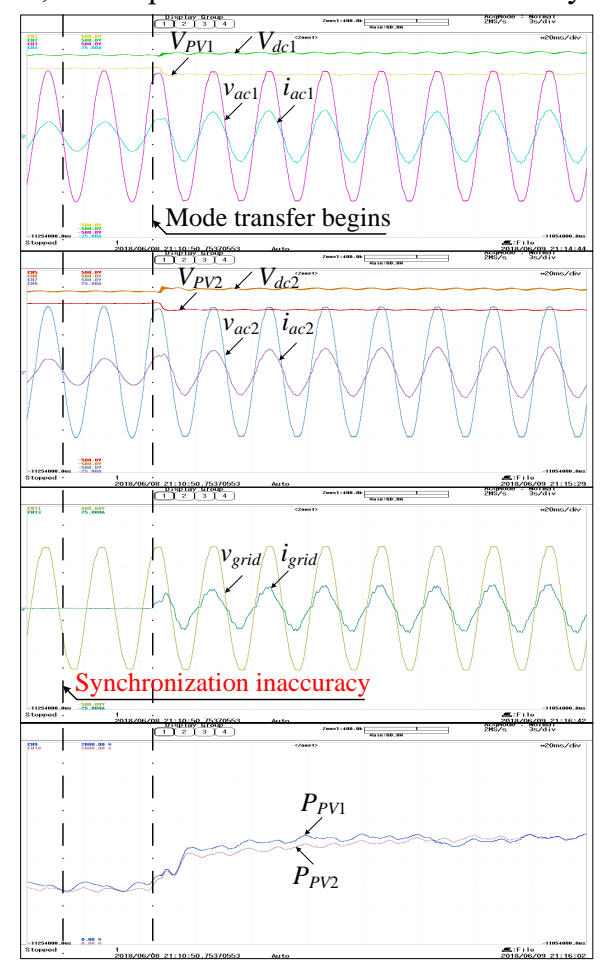

Fig. 21. Experimental results for transfer from islanded to grid-connected mode with a synchronization inaccuracy of grid-phase.
$P_{1}=1030 \mathrm{~W}$ and $P_{2}=1025 \mathrm{~W}$, from which $882 \mathrm{~W}$ flows to the grid. These powers are delivered by larger ac output currents of the two systems, and hence the grid current, as observed from Fig. 20(a). The expected decreases of PV terminal voltages from $335.2 \mathrm{~V}$ to $302.9 \mathrm{~V}$ and $335.9 \mathrm{~V}$ to $302.6 \mathrm{~V}$ have also been observed, but despite the decreases, the dc-link voltages have only been disturbed slightly. Likewise, the same seamless transfer has been observed from Fig. 20(b), during the return from grid-connected to islanded mode. Upon completed, the return causes the grid current to fall to zero and the total generated power to reduce from a maximum of $2145 \mathrm{~W}\left(P_{1}=\right.$ $1034 \mathrm{~W}$ and $\left.P_{2}=1011 \mathrm{~W}\right)$ to its initial value of $1164 \mathrm{~W}\left(P_{1}=\right.$ $578 \mathrm{~W}$ and $P_{2}=586 \mathrm{~W}$ ).

The transfer from islanded to grid-connected mode has then been repeated in Fig. 21 for demonstrating responses when the DG voltages have not been fully synchronized with the grid voltage at the instant of transfer. As noticed, the grid current has been deteriorated slightly at the beginning of the transfer, but it can restore a stable steady-state waveform after three fundamental cycles. Effectiveness of the proposed scheme has hence been demonstrated.

\section{CONCLUSION}

An alternative seamless scheme for regulating paralleled systems has been proposed, whose purpose is to identify a unified control core that will remain unchanged in both grid-connected and islanded modes. Each mode transfer will then require no changes of the control targets and structure. Instead, it can be viewed as a normal transient event experiencing a change of power (or source current) reference. Moreover, the generated power is always regulated by the front dc-dc converter connected directly to the source. The dc-link voltage is then always regulated by the rear inverter, which in addition, regulates the grid current directly when connected to the grid. A smoother transfer to grid connection can thus be ensured with any grid-synchronization inaccuracy merely appearing as a different power factor angle, rather than a surge in current normally linked to voltage regulation. The same direct regulation of output current when islanded has also been enforced, which together with the one-to-one mapping of the droop equation, has retained the necessary drooped voltage for power sharing. Simulation and experimental results have proven these expectations.

\section{REFERENCES}

[1] G. T. Heydt, "The next generation of power distribution systems," in IEEE Trans. Smart Grid, vol. 1, no. 3, pp. 225-235, Dec. 2010.

[2] E R. Teodorescu and F. Blaabjerg, "Flexible control of small wind turbines with grid failure detection operating in stand-alone and grid-connected mode," in IEEE Trans. Power Electron., vol. 19, no. 5, pp. 1323-1332, Sep. 2004.

[3] "IEEE standard for interconnecting distributed resources with electric power systems - Amendment 1," in IEEE Std 1547a-2014 (Amendment to IEEE Std 1547-2003), pp.1-16, May 21, 2014

[4] M. Hamzeh, N. Rashidirad, K. Sheshyekani and E. Afjei, "A new islanding detection scheme for multiple inverter-based DG systems," in IEEE Trans. Energy Convers., vol. 31, no. 3, pp. 1002-1011, Sep. 2016.

[5] M. Al Hosani, Z. Qu and H. H. Zeineldin, "Development of dynamic estimators for islanding detection of inverter-based DG," in IEEE Trans. Power Del., vol. 30, no. 1, pp. 428-436, Feb. 2015. 
[6] J. Wang, N. C. P. Chang, X. Feng and A. Monti, "Design of a generalized control algorithm for parallel inverters for smooth microgrid transition operation," in IEEE Trans. Ind. Electron., vol. 62, no. 8, pp. 4900-4914, Aug. 2015

[7] T. V. Tran, T. W. Chun, H. H. Lee, H. G. Kim and E. C. Nho, "PLL-based seamless transfer control between grid-connected and islanding modes in grid-connected inverters," in IEEE Trans. Power Electron., vol. 29, no. 10, pp. 5218-5228, Oct. 2014.

[8] S. Yoon, H. Oh and S. Choi, "Controller design and implementation of indirect current control based utility-interactive inverter system," in IEEE Trans. Power Electron., vol. 28, no. 1, pp. 26-30, Jan. 2013.

[9] Z. Liu and J. Liu, "Indirect current control based seamless transfer of three-phase inverter in distributed generation," in IEEE Trans. Power Electron., vol. 29, no. 7, pp. 3368-3383, Jul. 2014.

[10] X. Wang, C. Zhang, X. Li and Z. Guo, "Weighted control research on seamless transfer for dual-mode three phase inverter in micro-grid," in Proc. ICEMS Conf., Beijing, 2011, pp. 1-5.

[11] R. Majumder, A. Ghosh, G. Ledwich and F. Zare, "Control of parallel converters for load sharing with seamless transfer between grid connected and islanded modes," in Proc. IEEE PEESGM-CDEE Conf., Pittsburgh, PA, 2008, pp. 1-7.

[12] Q. N. Trinh, P. Wang, F. H. Choo, C. Jin, X. Pan and H. H. Lee, "A novel control strategy for smooth transition between stand-alone and grid-connected operations of distributed generation," in Proc. ICPE-ECCE-Asia Conf., Seoul, 2015, pp. 1276-1281.

[13] T. S. Hwang and S. Y. Park, "A seamless control strategy of a distributed generation inverter for the critical load safety under strict grid disturbances," in IEEE Trans. Power Electron., vol. 28, no. 10, pp. 4780-4790, Oct. 2013

[14] Y. A. R. I. Mohamed and A. A. Radwan, "Hierarchical control system for robust microgrid operation and seamless mode transfer in active distribution systems," in IEEE Trans. Smart Grid, vol. 2, no. 2, pp. 352-362, Jun. 2011.

[15] F. Tang, J. M. Guerrero, J. C. Vasquez, D. Wu and L. Meng, "Distributed active synchronization strategy for microgrid seamless reconnection to the grid under unbalance and harmonic distortion," in IEEE Trans. Smart Grid, vol. 6, no. 6, pp. 2757-2769, Nov. 2015.

[16] D. S. Ochs, B. Mirafzal and P. Sotoodeh, "A method of seamless transitions between grid-tied and stand-alone modes of operation for utility-interactive three-phase inverters," in IEEE Trans. Ind. Appl., vol. 50, no. 3, pp. 1934-1941, May/Jun. 2014.

[17] A. Micallef, M. Apap, C. Spiteri-Staines and J. M. Guerrero, "Single-phase microgrid with seamless transition capabilities between modes of operation," in IEEE Trans. Smart Grid, vol. 6, no. 6, pp. 2736-2745, Nov. 2015.

[18] S. S. Huang, Y. Konishi, Z. Z. Yang and M. J. Hsieh, "Observer-based capacitor current sensorless control applied to seamless transfer single-phase inverter system," in IEEE Trans. Power Electron., 2018 (Early Access).

[19] Z. Yao, L. Xiao and Y. Yan, "Seamless transfer of single-phase grid-interactive inverters between grid-connected and stand-alone modes," in IEEE Trans. Power Electron., vol. 25, no. 6, pp. 1597-1603, Jun. 2010.

[20] K. Kim, D. Shin, H. J. Kim, J. P. Lee, T. J. Kim and D. W. Yoo, “A seamless transfer algorithm based on active frequency detection with feedforward control method in distributed generation system," in Proc. EPE'17 ECCE-Europe Conf., Geneva, 2015, pp. 1-8.

[21] Y. Chen Z. Wang, X. Zhou, L. Zhou, Z. Chen, A. Lou, M. Wang, "Seamless transfer control strategy for three-phase inverter in microgrid," in Proc. IPEMC-ECCE Asia Conf., Hefei, 2016, pp. 1759-1763.

[22] S. Augustine, N. Lakshminarasamma and M. K. Mishra, "Control of photovoltaic-based low-voltage DC microgrid system for power sharing with modified droop algorithm," in IET Power Electron., vol. 9, no. 6, pp. 1132-1143, May 2016.

[23] A. Tah and D. Das, "An enhanced droop control method for accurate load sharing and voltage improvement of isolated and interconnected DC microgrids," in IEEE Trans. Susta. Energy, vol. 7, no. 3, pp. 1194-1204, Jul. 2016

[24] Y. Shi, W. Wu, H. Wang, Y. Du and J. Su, "The parallel multi-inverter system based on the voltage-type droop control method," in IEEE $J$ Emerg. Sel. Topics Power Electron., vol. 4, no. 4, pp. 1332-1341, Dec. 2016

[25] J. M. Guerrero, J. C. Vasquez, J. Matas, M. Castilla, and L. G. de Vicuna, "Control strategy for flexible microgrid based on parallel line-interactive UPS systems," in IEEE Trans. Ind. Electron., vol. 56, no. 3, pp. 726-736, Mar. 2009.
[26] C. Trujillo Rodriguez, D. Velasco de la Fuente, G. Garcera, E. Figueres and J. A. Guacaneme Moreno, "Reconfigurable control scheme for a PV microinverter working in both grid-connected and island modes," in IEEE Trans. Ind. Electron., vol. 60, no. 4, pp. 1582-1595, Apr. 2013.

[27] D. Velasco de la Fuente, C. L. Trujillo Rodríguez, G. Garcerá, E. Figueres and R. Ortega Gonzalez, "Photovoltaic power system with battery backup with grid-connection and islanded operation capabilities," in IEEE Trans. Ind. Electron., vol. 60, no. 4, pp. 1571-1581, Apr. 2013.

[28] F. Luo, Y. M. Lai, K. H. Loo, C. K. Tse and X. Ruan, "A generalized droop-control scheme for decentralized control of inverter-interfaced microgrids," in Proc. ISCAS Conf., Beijing, 2013, pp. 1320-1323.

[29] H. Liu, Y. Yang, X. Wang, P. C. Loh, F. Blaabjerg, W. Wang and D. Xu, "An enhanced dual droop control scheme for resilient active power sharing among paralleled two-stage converters," in IEEE Trans. Power Electron., vol. 32, no. 8, pp. 6091-6104, Aug. 2017.

[30] J. Rocabert, A. Luma, F. Blaabjerg, and P. Rodriguez, "Control of power converters in ac microgrids," IEEE Trans. Power Electron., vol. 27, no. 11, pp. 4734-4749, Nov. 2012.

[31] P. Sreekumar and V. Khadkikar, "A new virtual harmonic impedance scheme for harmonic power sharing in an islanded microgrid," IEEE Trans. Power Del., vol. 31, no. 3, pp. 936-945, Jun. 2016.

[32] H. Akagi, H. Fujita, and K. Wada, "A shunt active filter based on voltage detection for harmonic termination of a radial power distribution line," IEEE Trans. Ind. Appl., vol. 35, no. 3, pp. 638-645, May/Jun. 1999.

[33] Z. Zeng, R. Zhao, Z. Lv, and L. Ma, "Impedance reshaping of grid-tied inverters to damp the series and parallel harmonic resonances of photovoltaic systems," Proc. of CSEE, vol. 34, no. 27, pp. 4547-4558, Sep. 2014.

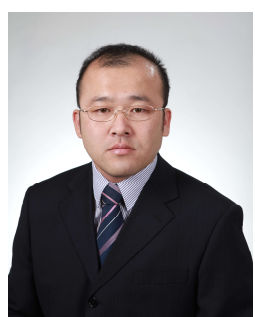

Hongpeng Liu (M'13) received his B.S. degree in Electrical Engineering from Harbin University of Science and Technology, Harbin, China, in 2000, and his M.S. and Ph.D. degrees in Electrical Engineering from Harbin Institute of Technology, Harbin, China, in 2006 and 2011, respectively. In 2011, he joined Harbin Institute of Technology as an Assistant Professor in the Department of Electrical Engineering, where he was an Associate Professor since December 2016. His current research interests include converter/inverter systems. photovoltaic generation, Micro-grid, and PWM

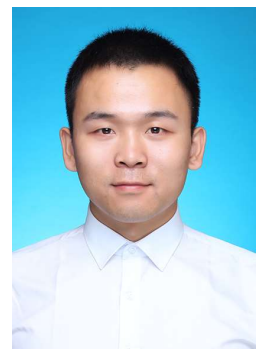

Wei Zhang received his B.S. degree in Control Science and Engineering from Harbin Institute of Technology, Harbin, China, in 2012, and his M.S. degree in Control Science and Control Engineering from Harbin Engineering University in 2015. He is currently working toward the Ph.D. degree in electrical engineering at Harbin Institute of Technology. His current research interests include regenerative energy converter techniques, micro-grid. 


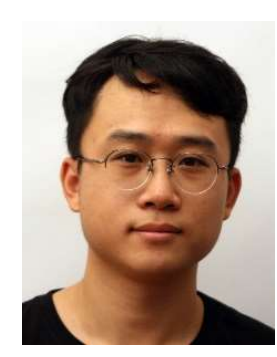

Bainnan Sun (S'17) received the B.S. and M.S degrees in electrical engineering from Harbin Institute of Technology, Harbin, China in 2015 and 2017 , respectively. He is currently working toward the Ph.D. degree in power electronics at Technical University of Denmark, Kgs. Lyngby, Denmark. His current research interests include wide bandgap semiconductor transistor and high power density inverter.

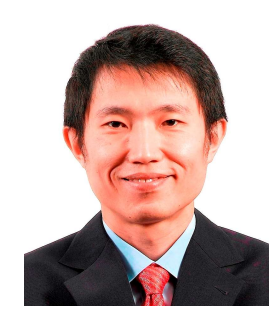

Poh Chiang Loh received his B. Eng (Hons) and M.Eng from the National University of Singapore in 1998 and 2000 respectively, and his Ph.D from Monash University, Australia, in 2002, all in electrical engineering. His interests are in power converters and their grid applications.

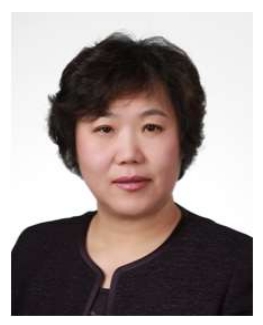

Wei Wang (M'13) received her B.S. degree in Automatic Test and Control from Harbin Institute of Technology, Harbin, China, in 1984, her M.S. degree in Electrical Engineering from Harbin Institute of Technology in 1990, and her Ph.D. degree in Mechanical Electronic Engineering from Harbin Institute of Technology in 2002. In 1984, she joined Harbin Institute of Technology, as an Assistant Professor in the Department of Electrical Engineering, where she was an Associate Professor from 1995 to 2003, and where she has been a Professor since 2003. Her current research interests include regenerative energy converter techniques, micro-grid, soft-switching converters, and lighting electronic technology.

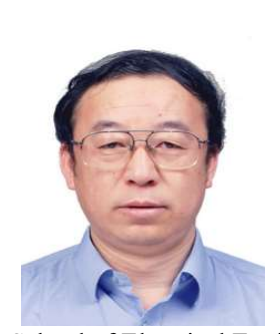

Dianguo Xu (M'97-SM'12-F'17) received the B.S. degree in Control Engineering from Harbin Engineering University, Harbin, China, in 1982, and the M.S. and Ph.D. degrees in Electrical Engineering from Harbin Institute of Technology (HIT), Harbin, China, in 1984 and 1989 respectively.

In 1984, he joined the Department of Electrical Engineering, HIT as an assistant professor. Since 1994, he has been a professor in the Department of Electrical Engineering, HIT. He was the Dean of School of Electrical Engineering and Automation, HIT from 2000 to 2010. He is now the vice president of HIT. His research interests include renewable energy generation technology, multi-terminal HVDC system based on VSC, power quality mitigation, speed sensorless vector controlled motor drives, high performance PMSM servo system. He published over 600 technical papers.

Prof. $\mathrm{Xu}$ is an Associate Editor of the IEEE Transactions on Industrial Electronics and the IEEE Journal of Emerging and Selected Topics in Power Electronics. He also serves as Chairman of IEEE Harbin Section, Director of Lighting Power Supply Committee of CPSS, Vice-director of Electric Automation Committee of CAA, Electrical Control System \& Equipment Committee of CES, and Power Electronics Committee of CES.

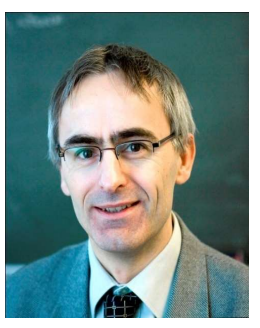

Frede Blaabjerg (S'86-M'88-SM'97-F'03) was with ABB-Scandia, Randers, Denmark, from 1987 to 1988 . From 1988 to 1992 , he was a Ph.D. Student with Aalborg University, Aalborg, Denmark. He became an Assistant Professor in 1992, Associate Professor in 1996, and Full Professor of power electronics and drives in 1998. His current research interests include power electronics and its applications such as in wind turbines, PV systems, reliability, harmonics and adjustable speed drives.

He has received 17 IEEE Prize Paper Awards, the IEEE PELS Distinguished Service Award in 2009, the EPE-PEMC Council Award in 2010, the IEEE William E. Newell Power Electronics Award 2014 and the Villum Kann Rasmussen Research Award 2014. He was an Editor-in-Chief of the IEEE TRANSACTIONS ON POWER ELECTRONICS from 2006 to 2012. He is nominated in 2014 and 2015 by Thomson Reuters to be between the most 250 cited researchers in Engineering in the world. 